\title{
Anatomy of the hypothalamus and pituitary gland
}

\author{
P. M. DANIEL
}

From the Department of Applied Physiology and Surgical Science, Royal College of Surgeons of England, Lincoln's Inn Fields, London WC2A 3PN

Some knowledge of the anatomy of the hypothalamus and pituitary and of the neurovascular pathways connecting them is essential for understanding the endocrine and other dysfunctions that result from any lesion involving either the hypothalamus or the pituitary or which damages their connecting pathways. When the pituitary gland is removed or is deprived of stimuli from the hypothalamus 'hypopituitarism' results. In hypopituitarism the endocrine organs show the most striking changes, but all the tissues of the body are affected to a greater or lesser extent (Sheehan, 1937; Sheehan and Summers, 1949; Daniel and Prichard, 1975).

The anterior lobe (pars distalis) of the pituitary gland develops as an upgrowth of epithelial tissue from the primitive pharynx (Rathke's pouch) which
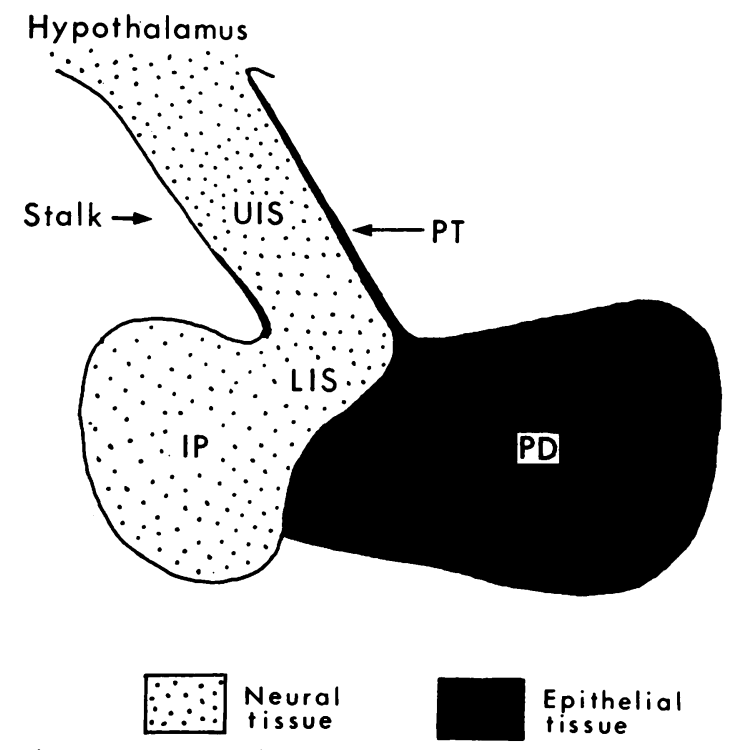

Fig. 1 Diagram of human pituitary gland in sagittal section. 'Neural tissue' indicates the neurohypophysis; 'epithelial tissue' the adenohypophysis. IP = infundibular process (posterior lobe). LIS = lower infundibular stem. $P D=$ pars distalis (anterior lobe). $P T=$ pars tuberalis. UIS = upper infundibular stem. meets a downgrowth from the base of the brain, the latter being destined to form not only the infundibular process (posterior, or neural, lobe) of the pituitary but also the neural part of the pituitary stalk. The early arrangements in the human have been illustrated by Daniel (1966a). The parts of the adult human pituitary gland and of the pituitary stalk are shown in Fig. 1. The nomenclature of these structures is confusing and some of the names which have been applied to certain parts of the pituitary complex and the hypothalamus in animals should not be transferred uncritically to man. Daniel and Prichard (1975) have explained the names of the various parts of these structures.

\section{Hypothalamus}

The hypothalamus lies at the base of the brain, around the third ventricle, extending from a plane immediately anterior to the optic chiasma to one immediately posterior to the mamillary bodies. Laterally its borders, somewhat ill-defined, are roughly the optic tract, the internal capsule, pes pedunculi, globus pallidus, and ansa penduncularis at various anteroposterior planes, while superiorly it does not extend above the level of the anterior commissure. Its weight in the adult human is less than $2.5 \mathrm{~g}$. Lévêque (1974) thinks that the hypothalamus should be given the status of an endocrine organ, while Stumpf (1975) suggests that the whole brain should be regarded as an endocrine gland.

NERVE CELLS OF THE HYPOTHALAMUS

The small mass of cerebral tissue which comprises the hypothalamus contains some extremely welldefined nuclei but also others whose outline cannot be so easily determined. Some of the latter stand out more clearly in the fetus than in the adult (Clark, 1938). The general arrangements of the more readily identifiable nuclei are shown in Figs. 2 and 3. The most striking of all are the supraoptic, composed almost wholly of large nerve cells, and the paraventricular nuclei, composed mainly of large nerve 


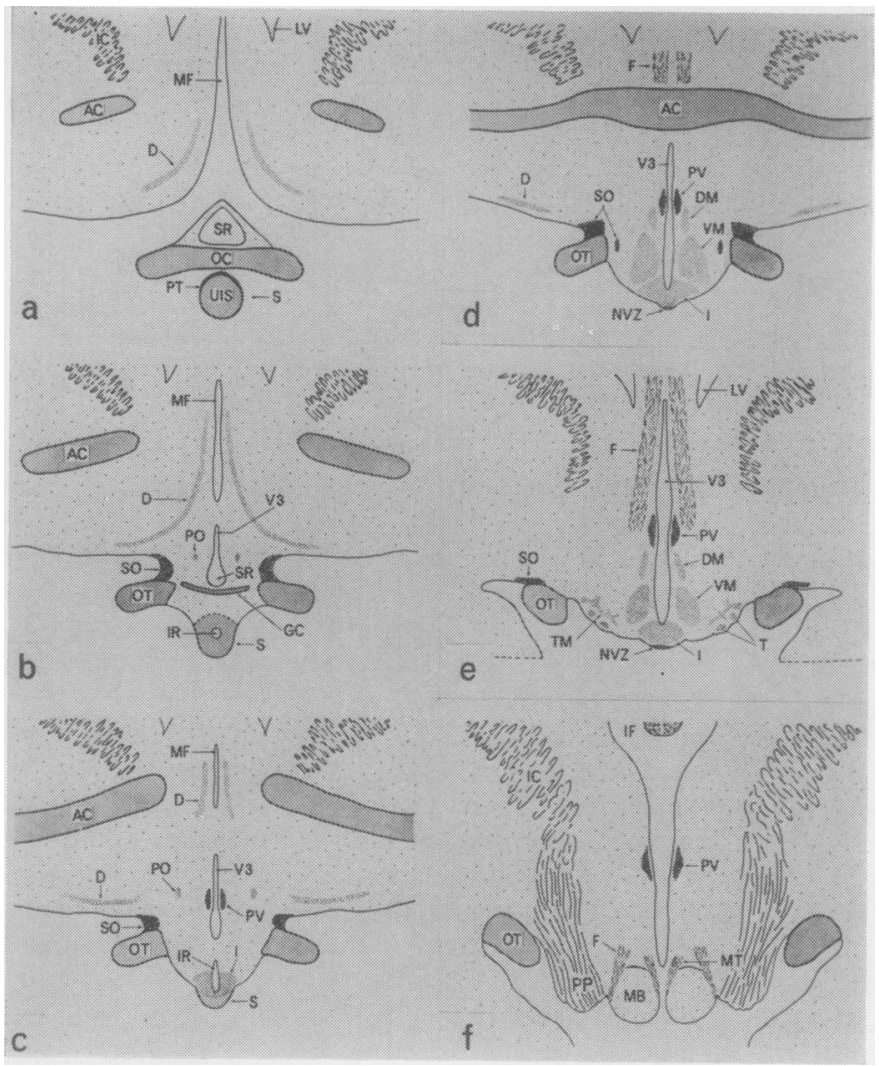

Fig. 2 Human hypothalamus and adjacent parts in coronal planes. Sequence of diagrams showing main landmarks and structures in anteroposterior sections ( $a$ to $f$ ) based on study of serial sections of many normal human cases (see also Fig. 3) $A C=$ anterior commissure. $D=$ nucleus of diagonal band of Broca. $D M=$ dorsomedial nucleus. $F=$ anterior column of fornix.

$G C=$ Gudden's commissure. $I=$ infundibular nucleus. IC = internal capsule. $I F=$ intraventricular foramen. $I R=$ infundibular recess of third ventricle. $L V=$ lateral ventricle. $M B=$ mamillary body.

$M F=$ midline fissure separating the two hemispheres. $M I=$ massa intermedia and part of thalamus. $M T=$ mamillo-thalamic tract. $N V Z=$ neurovascular zone.

$O C=$ optic chiasma. $O N=$ optic nerve.

$O T=$ optic tract. $P O=$ preoptic nucleus. $P P=$ pes pedunculi. $P T=$ pars tuberalis. $P V=$ paraventricular nucleus. $S=$ pituitary stalk. $S O=$ supraoptic nucleus.

$S R=$ supraoptic recess of third ventricle. $T=$ lateral tuberal nucleus. $T M=$ tubero-mamillary cells. UIS = upper infundibular stem (neural tissue of pituitary stalk). $V M=$ ventromedial nucleus. $V_{3}=$ third ventricle.

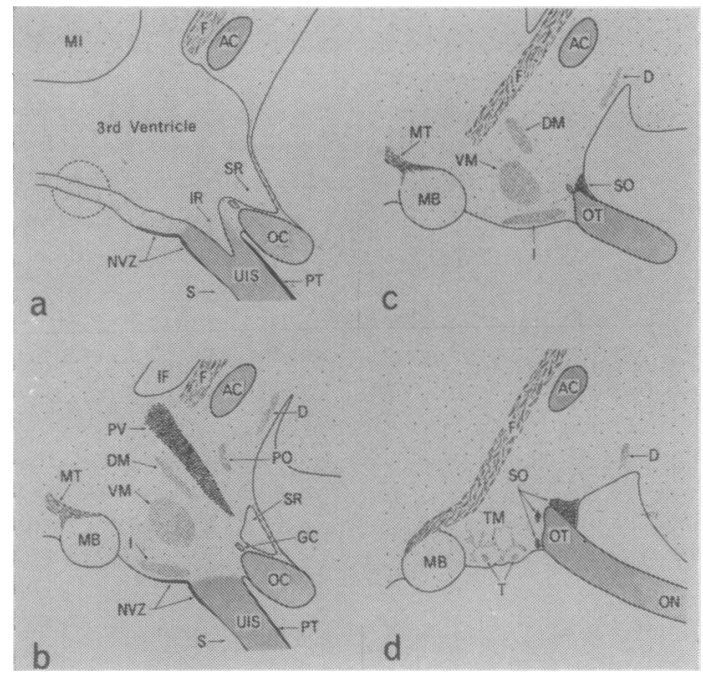

Fig. 3 Human hypothalamus and adjacent parts in sagittal planes traced from median plane laterally (a to d; anterior to right). For key to lettering see Fig. 2. 
cells but also with a number of smaller cells. The large cells of these nuclei synthesise vasopressin and oxytocin and also a binding protein, neurophysin, which is rich in cystine (Hope, 1975; Watkins, 1975; Zimmerman et al., 1975).

This complex of substances, but probably mainly the neurophysin, can be stained by Gomori's chromealum-haematoxylin method. Since this complex passes down the axons of the cells into the hypothalamo-neurohypophysial tract on its way to end by entering the capillaries of the infundibular process the course of the axons, both in the hypothalamus and the tract, may be traced by this means. The classical studies on neurosecretion by the Scharrers and by Bargmann are reviewed by Stutinsky (1974), as is more recent work.

There are still many puzzling features about neurosecretion. For example, in the normal adult human hypothalamus and hypothalamo-neurohypophysial tract few cells or nerve fibres take the stain for neurosecretory material, although in children and in cases of hypophysectomy or section of the pituitary stalk the picture is different (Daniel and Prichard, 1975). Knowles and Vollrath (1974) review neurosecretion.

The nuclei in the basal part of the hypothalamus, especially those in the tuber cinereum (around the

Hypothalamus

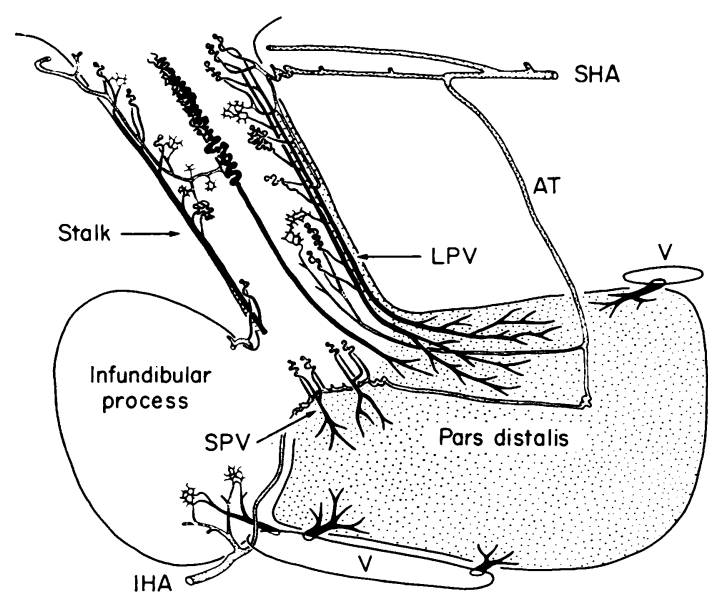

Fig. 4 Human pituitary gland. Diagram in sagittal section showing main features of blood supply. Note sinusoids of the pars distalis are supplied by two groups of portal vessels: long portal vessels (LPV) draining characteristic capillary loops in the upper infundibular stem (neural tissue of stalk) and short portal vessels $(S P V)$ draining similar capillary loops in lower infundibular stem. $A T=$ artery of the trabecula. $I H A=$ inferior hypophysial artery. SHA = superior hypophysial artery. $V=$ venous sinus.

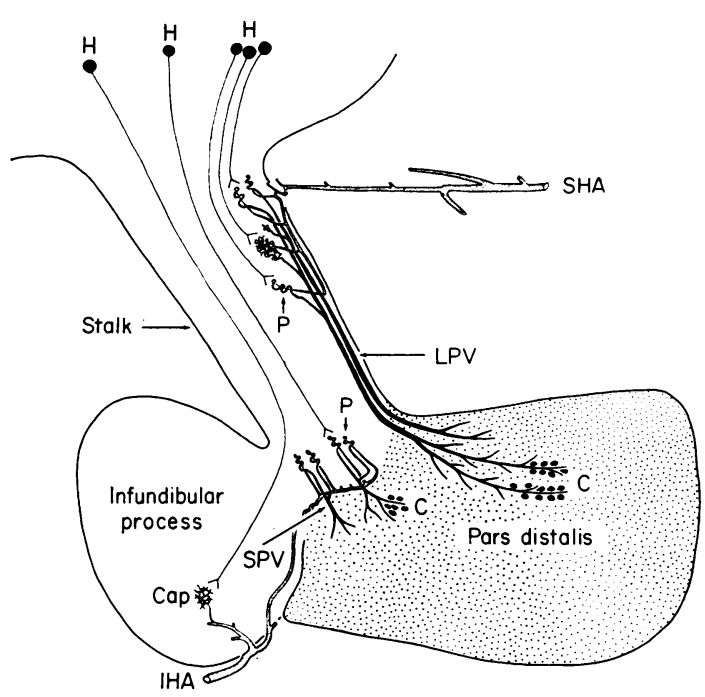

Fig. 5 Diagram of human pituitary gland in sagittal plane showing neurovascular pathways by which nerve cells in certain hypothalamic nuclei $(H)$ control output of anterior and posterior pituitary hormones. Axon on left ending on the capillary bed (Cap) in the infundibular process represents the tract from the large nerve cells of the supraoptic and paraventricular nuclei, which are concerned with posterior pituitary function. The other axons have their origin in nerve cells in the so-called hypophysiotrophic area of the hypothalamus and end on the primary capillary bed $(P)$ feeding the portal vessels which supply the pars distalis. Here their neurohormones are transmitted into the blood stream and are then carried through the long and the short portal vessels $(L P V, S P V)$ to the epithelial cells $(C)$ in a given area of the pars distalis to control the output of hormones from these cells.

infundibular recess) and in the adjacent parts (Figs. $2,3)$ are concerned mainly with the production of the releasing and inhibiting factors (neurohormones) which control the activities of the pars distalis, the anterior lobe. This region has been called the 'hypophysiotrophic area' and information on its activites has been derived almost entirely from animal work (Szentágothai et al., 1968; Halász et al., 1975). However, Okon and Koch (1976) have recently localised gonadotropin-releasing hormones in this area of the human brain. Halász et al. (1975) describe some of the afferent connections of this area. The efferent nerve fibres from the nuclei of the hypophysiotrophic area are non-myelinated and join the fibres of the hypothalamo-neurohypophysial tract to end on the coiled capillaries which form the primary capillary bed of the long and short portal vessels (Figs. 4, 5). 
The identifiable nuclei of the hypothalamus lie among numerous small nerve cells, which are not grouped into recognisable nuclei, and among fine nerve fibres which, in the main, are non-myelinated. A few tracts composed of myelinated fibres, such as the fornix and the mamillo-thalamic tract (Figs. 2,3 ), pass through the hypothalamus, in which they originate or end.

There has recently been renewed interest in the function of some of the specialised cells of the ependyma of the third ventricle. Certain of these cells pass their secretions into the cerebrospinal fluid and others appear to send processes which end on coiled capillaries, and perhaps on other capillaries, into which they probably pass their secretions. Rodríguez (1976) gives a valuable review of the subject, while Kumar and Kumar (1975) report interesting findings about the so-called 'tanycyte ependyma'.

AFFERENT AND EFFERENT NEURAL PATHWAYS OF THE HYPOTHALAMUS

The major afferent tracts tend to lie in the lateral parts of the hypothalamus while the efferent tracts lie nearer to the midline, although large numbers of both afferent and efferent non-myelinated nerve fibres connect the hypothalamic nerve cells with the various parts of the cerebral hemispheres, brain stem, and elsewhere and form a sort of capsule of nerve fibres around the hypothalamus. Relatively few of the neural pathways in the human hypothalamus are known in detail, and much of our knowledge of hypothalamic connections has had to be gained from animal experimental work (Raisman, 1966). Much remains to be learned from careful morphological studies of the human hypothalamus, especially from brains in which lesions have occurred which might be termed 'experiments of nature' (Daniel and Treip, 1977). There are various single studies on human material and Clark (1948) has reviewed some of the connections of the hypothalamus with the frontal lobes of the brain.

A massive tract of myelinated fibres, the fornix brings impulses from each temporal lobe to the ipsilateral mamillary body. One major efferent tract, more medially situated, is the mamillothalamic tract. It is composed of myelinated fibres and connects each mamillary body with the ipsilateral anterior nucleus of the thalamus, from which impulses are relayed to the frontal lobes. That there are efferent hypothalamo-autonomic tracts passing down the spinal cord directly to the preganglionic nuclei of the sympathetic and parasympathetic systems has recently been confirmed by Saper $e t$ al. (1976).

Another major efferent tract, composed almost entirely of non-myelinated nerve fibres, is the hypothalamo-neurohypophysial tract formed by the axons of neurosecretory nerve cells in the supraoptic and paraventricular nuclei which carry neurohormones to the neural lobe (infundibular process) of the pituitary. This important neuroendocrine tract carries vasopressin and oxytocin, the hormones which are destined to be released into the blood stream in the neural lobe or infundibular process (Figs. 4, 5). The hypothalamo-neurohypophysial tract is joined by fibres of the tubero-infundibular tract arising from nerve cells situated in the hypophysiotrophic areas, which are destined to end on coiled capillaries (Fig. 5).

BLOOD SUPPLY OF THE HYPOTHALAMUS The arterial supply is derived from the perforating vessels which spring from the various parts of the circle of Willis and pass through the anterior and posterior perforated substances. In addition to these small arteries two vessels, the superior hypophysial arteries, which arise from the internal carotid arteries, form an arterial ring around the tuber cinereum. Branches from this ring supply the optic chiasma and the adjacent parts of the hypothalamus. Many small arterial twigs from the ring pass into the pituitary stalk (Figs. 4, 6). The venous drainage enters into fairly large veins running in the basal cisterns (Duvernoy, 1975). Daniel (1963, 1966a, b) gives further details of the blood supply.

\section{Pituitary Gland}

The general arrangements of the pituitary gland are shown diagrammatically in Fig. 1. The epithelial cells forming the anterior lobe of the gland, or pars distalis, secrete their hormones directly into the blood flowing through the sinusoids that run between the cells (Figs. 5, 7). The granules within these cells identify the various types of cell. These granules however, are difficult to study in human glands since it is not easy to obtain fresh specimens. Conklin $(1966,1968)$ gives useful descriptions of these cells in the human (see also Doniach, 1977). The literature on the cells of the pars distalis in animals is vast, though relatively little work has been done on human material. The cells of the infundibular process have been rather neglected in recent years, but Daniel and Prichard (1975) give some data on their reactions.

Neurovascular link between hypothalamus and pituitary gland

The pituitary stalk comprises mainly neural and vascular components, though an incomplete layer of 
epithelial cells, the pars tuberalis, whose function is uncertain, covers its ventral aspect (Figs. 1, 5). The bulk of the stalk is made up of neural tissue in which lie the various coiled capillary vessels on which end the nerve fibres that are derived from cells in the hypophysiotrophic area. The neurohormones coming down these nerve fibres are transferred from the endings of the fibres into the blood passing through the coiled capillaries, and thus into the portal vessels. These portal vessels, as was first pointed out by Xuereb et al. (1954b), can be classified as long and short (Fig. 4). The origin of the vessels which supply them makes a distinction most important. The afferent arterioles to the coiled capillaries from which the long portal vessels are derived spring from the arterial ring supplied by the superior hypophysial arteries (arising from the internal carotid arteries above the level of the diaphragma sellae), while those which supply the coiled capillaries that form the short portal vessels are derived from the inferior hypophysial arteries, which leave the internal carotid arteries within the cavernous sinus. The long portal vessels run down the pituitary stalk to supply the larger part of the pars distalis, while the short portal vessels supply a restricted part of the lobe adjacent to that part of the lower infundibular stem which is buried in the pars distalis (Fig. 4). Xuereb et al. (1954a, b) describe this system of vessels, and Daniel and Prichard (1975) also describe the system in other species. A portal system of vessels is found in all vertebrates, and a valuable recent study is of that in the horse (Vitums, 1975).

When the pituitary stalk is cut surgically, to try to produce regression of various forms of carcinoma

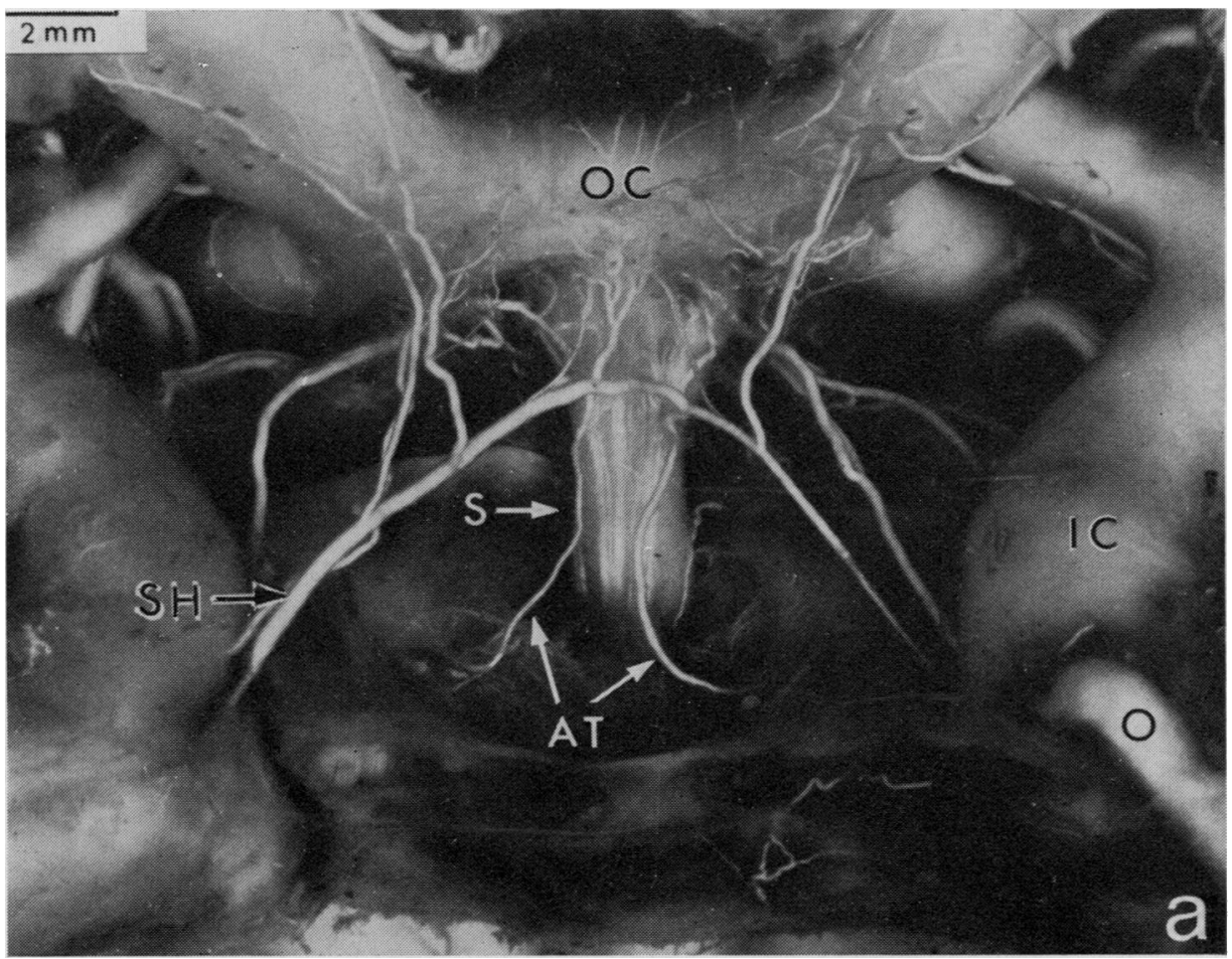

Fig. 6 Injected, partially macerated preparation of human pituitary gland showing some of the main features of the vascular arrangements. Gland and neighbouring structures are viewed from the front. Note superior hypophysial artery $(\mathrm{SH})$ springing from the internal carotid artery (IC) on each side, anastomosing in front of the pituitary stalk $(S)$, and giving off branches to supply a primary capillary bed (not visible here) within the stalk. The long portal vessels which drain this bed and run down the stalk into the pars distalis are better seen in Fig. 7. The artery of the trabecula $(A T)$, although plunging into the pars distalis, does not deliver blood directly to this lobe, which has a purely portal venous blood supply (see Fig. 4.) $O=$ ophthalmic artery. $O C=$ optic chiasma. 
or halt the progress of diabetic retinopathy, all the blood coming down the stalk in the long portal vessels is cut off and a large infarct is formed in the pars distalis involving up to $90 \%$ of the lobe. The afferent blood supply to the short portal vessels, however, is spared so that they continue to transmit blood and the small part of the pars distalis which they supply remains viable (Daniel and Prichard, 1975).

In one interesting case of head injury, reported by Daniel et al. (1959), the pituitary stalk had been torn across above the level of the arterial ring derived from the superior hypophysial arteries (Fig. 4). Thus the afferent arterial supply to the coiled capillaries in the stalk, which gives origin to the long portal vessels, was preserved and an infarct had not developed in the pars distalis.

Although a small part of the pars distalis survives after transsection of the pituitary stalk the surviving

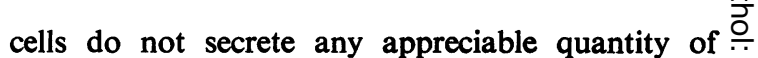
hormones, since the nerve fibres bringing neuro- $\overrightarrow{\vec{F}}$ hormones down the stalk have been severed and the cells are thereby effectively 'denervated'-that is, 등 the blood supplying them does not contain releasing $\overline{\bar{c}}$ or inhibiting factors (Daniel and Prichard, 1975). It should be noted that there is no appreciable direct arterial supply to the pars distalis.

Advances in knowledge of the pathological $\overrightarrow{0}$ changes in the human hypothalamus and pituitary $\vec{\overrightarrow{ }}$ can be made only by experts in the field. Daniel $\vec{\omega}$ and Prichard (1975) indicate the difficult and time consuming nature of the necessary investigations.

Much of the work on which this paper is based was done with the assistance of grants from the Nuffield 0 Foundation and from the Research Fund of the Bethlem Royal and Maudsley Hospitals.

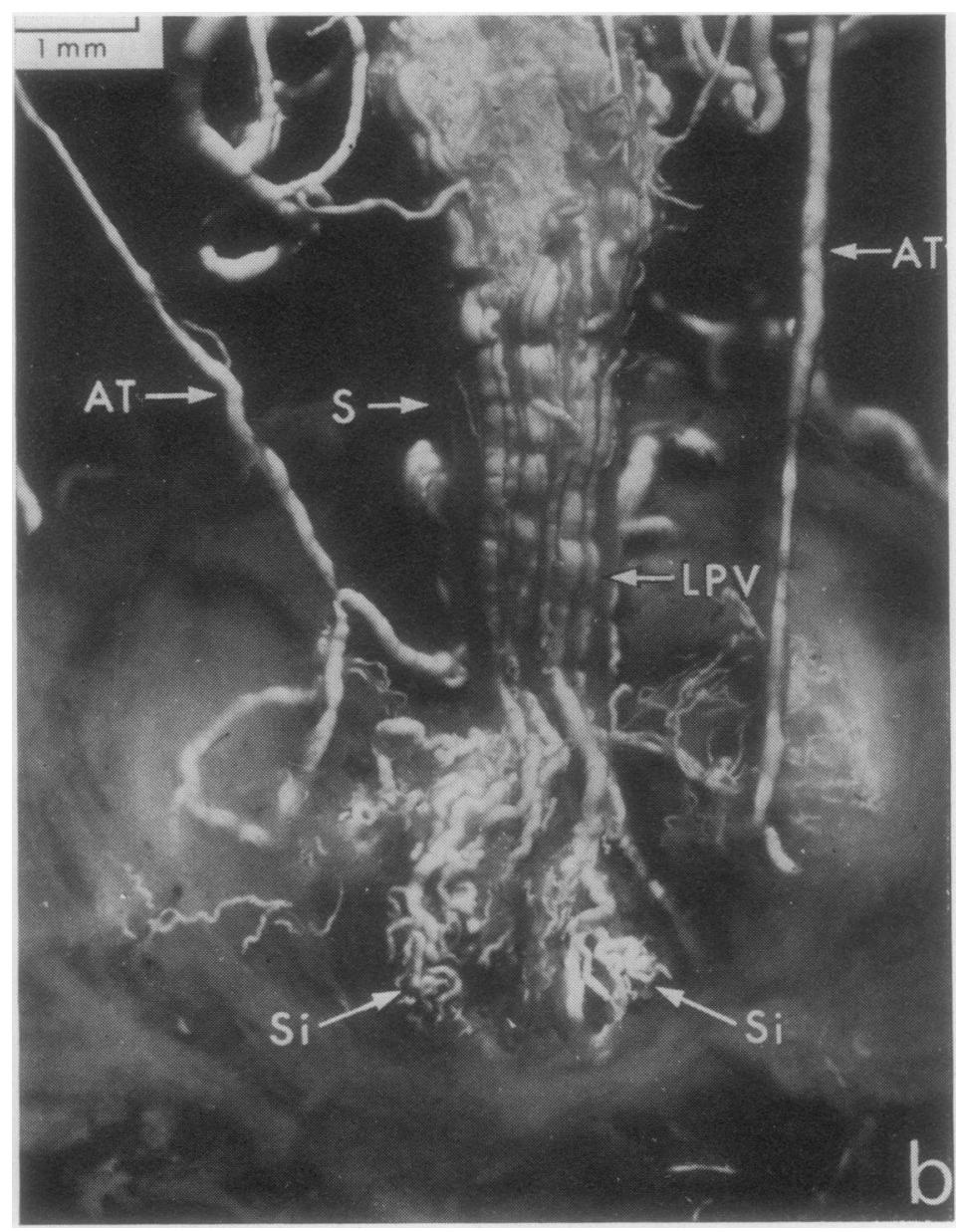

Fig. 7 Injected, partially macerated preparation of human pituitary gland seen from the front showing some of the main features of the vascular arrangements. The long portal vessels (LPV) run down the stalk $(S)$ and break up into the sinusoids (Si) of pars distalis. $A T=$ artery of the trabecula. 


\section{References}

Clark, W. E. le Gros (1938). Morphological aspects of the hypothalamus. In The Hypothalamus. Morphological, Functional, Clinical and Surgical Aspects. By W. E. le Gros Clark, J. Beattie, G. Riddoch, and N. M. Dott, p. 1. Oliver and Boyd, Edinburgh.

Clark, W. E. le Gros (1948). The connexions of the frontal lobes of the brain. Lancet, 1, 353.

Conklin, J. L. (1966). The identification of acidophilic cells in the human pars distalis. Anatomical Record, 156, 347.

Conklin, J. L. (1968). A histochemical study of mucoid cells in the pars distalis of the human hypophysis. Anatomical Record, 160, 59.

Daniel, P. M. (1963). The pituitary gland and its blood supply. In Scientific Basis of Medicine Annual Reviews 1963, 83.

Daniel, P. M. (1966a). The blood supply of the hypothalamus and pituitary gland. British Medical Bulletin, 22, 202.

Daniel, P. M. (1966b). The anatomy of the hypothalamus and pituitary gland. In Neuroendocrinology. Ed. L. Martini and W. F. Ganong, vol. 1, p. 15. Academic Press, New York.

Daniel, P. M., and Prichard, M. M. L. (1975). Studies of the Hypothalamus and the Pituitary Gland. Alden Press, Oxford. (also Acta Endocrinologica, 80, Supplement 201).

Daniel, P. M., Prichard, M. M. L., and Treip, C. S. (1959). Traumatic infarction of the anterior lobe of the pituitary gland. Lancet, 2, 927.

Daniel, P. M., and Treip, C. S. (1977). The pathology of the hypothalamus. Clinics in Endocrinology and Metabolism, $6,3$.

Doniach, I. (1977). Histopathology of the anterior pituitary. Clinics in Endocrinology and Metabolism, 6, 21.

Duvernoy, H. M. (1975). The Superficial Veins of the Human Brain. Springer, Berlin and New York.

Halász, B., Köves, K., Réthely, M., Bodoky, M., and Koritsánszky, S. (1975). Recent data on neuronal connections between nervous structures involved in the control of the adenohypophysis. In Anatomical Neuroendocrinology. Ed. W. E. Stumpf and L. D. Grant. Karger, Basle, London, New York.

Hope, D. B. (1975). The neurophysin proteins: historical aspects. Annals of the New York Academy of Sciences, 248, 6.

Kumar, K., and Kumar, T. C. A. (1975). The habenular ependyma: a neuroendocrine component of the epithalamus in the rhesus monkey. In Anatomical Neuroendocrinology. Ed. W. E. Stumpf and L. D. Grant. Karger, Basle, London, New York.

Knowles, F., and Vollrath, L. (1974). Neurosecretion-the Final Neuroendocrine Pathway. Springer, Berlin, Heidelberg, New York.
Lévêque, T. F. (1974). The endocrine hypothalamus: an historical review. Canadian Journal of Neurological Sciences, 1, 24.

Okon, E., and Koch, Y. (1976). Localisation of gonadotropin-releasing and thyrotropin-releasing hormones in human brain by radioimmunoassay. Nature, 263, 345 .

Raisman, G. (1966). Neural connexions of the hypothalamus. British Medical Bulletin, 22, 197.

Rodríguez, E. M. (1976). The cerebrospinal fluid as a pathway in neuroendocrine integration. Journal of Endocrinology, 71, 407.

Saper, C. B., Loewy, A. D., Swanson, L. W., and Cowan, W. M. (1976). Direct hypothalamo-autonomic connections. Brain Research, 117, 305.

Sheehan, H. L. (1937). Post-partum necrosis of the anterior pituitary. Journal of Pathology and Bacteriology, 45, 189.

Sheehan, H. L., and Summers, V. K. (1949). The syndrome of hypopituitarism. Quarterly Journal of Medicine, 18, 319.

Stumpf, W. E. (1975). The brain: an endocrine gland and hormone target. In Anatomical Neuroendocrinology, Ed. W. E. Stumpf and L. D. Grant. Karger, Basle, London, New York.

Stutinsky, F. (1974). Morphological and physiological reactions of the supraoptic and paraventricular nuclei. In Neurosecretion-the Final Neuroendocrine Pathway. Ed. F. Knowles and L. Vollrath. Springer, Berlin and New York.

Szentágothai, J., Flerkó, B., Mess, B., and Halász, B. (1968). Hypothalamic Control of the Anterior Pituitary. Académiai Kiadó, Budapest.

Vitums, A. (1975). Observations on the equine hypophysial portal system. Anatomy, Histology, and Embryology, 4, 149.

Watkins, W. B. (1975). Neurosecretory neurons in the hypothalamus and median eminence of the dog and sheep as revealed by immunohistochemical methods. Annals of the New York Academy of Sciences, 248, 134.

Xuereb, G. P., Prichard, M. M. L., and Daniel, P. M (1954a). The arterial supply and venous drainage of the human hypophysis cerebri. Quarterly Journal of Experimental Physiology, 39, 199.

Xuereb, G. P., Prichard, M. M. L., and Daniel, P. M. (1954b). The hypophysial portal system of vessels in man. Quarterly Journal of Experimental Physiology, 39, 219.

Zimmerman, E. A., Defendini, R., Sokol, H. W., and Robinson, A. G. (1975). The distribution of neurophysinsecreting pathways in the mammalian brain: light microscopic studies using the immunoperoxidase technique. Annals of the New York Academy of Sciences, 248, 92. 